\title{
'Candidatus Phytoplasma oryzae', a novel phytoplasma taxon associated with rice yellow dwarf disease
}

Correspondence

Shigetou Namba snamba@ims.u-tokyo.ac.jp

\author{
Hee-Young Jung, ${ }^{1}$ Toshimi Sawayanagi, ${ }^{2}$ Porntip Wongkaew, ${ }^{3}$ \\ Shigeyuki Kakizawa, ${ }^{2}$ Hisashi Nishigawa, ${ }^{2}$ Wei Wei, ${ }^{1}$ Kenro Oshima, ${ }^{2}$ \\ Shin-ichi Miyata, ${ }^{2}$ Masashi Ugaki, ${ }^{2}$ Tadaaki Hibi ${ }^{1}$ and Shigetou Namba ${ }^{2}$ \\ ${ }^{1}$ Laboratory of Plant Pathology, The University of Tokyo, 1-1-1 Yayoi, Bunkyo-ku, Tokyo \\ 113-8657, Japan \\ ${ }^{2}$ Laboratory of Bioresource Technology, The University of Tokyo, 202 Bioscience Building, \\ 5-1-5 Kashiwanoha, Kashiwa, Chiba 277-8562, Japan \\ ${ }^{3}$ Department of Plant Pathology, Khon Kaen University, Khon Kaen 40002, Thailand
}

In addition to rice yellow dwarf (RYD) phytoplasma, several phytoplasmas infect gramineous plants, including rice orange leaf, bermuda grass white leaf, brachiaria grass white leaf and sugarcane white leaf phytoplasmas. To investigate whether the RYD phytoplasma is a discrete, species-level taxon, several isolates of the aforementioned phytoplasmas were analysed using PCR-amplified 16S rDNA sequences. Two RYD isolates, RYD-J' and RYD-Th, were almost identical (99.2\%), but were distinct (similarities of 96.3-97.9\%) from other phytoplasma isolates of the RYD 16Sgroup. The notion that the RYD phytoplasma constitutes a unique taxon is also supported by its unique insect vector (Nephotettix sp.), its unique host plant in nature (rice) and its limited geographical distribution (Asia). In Southern blot analysis, chromosomal and extrachromosomal DNA probes of the RYD phytoplasma reportedly did not hybridize with those of closely related phytoplasmas. These properties of the RYD phytoplasma clearly indicate that it represents a novel taxon, 'Candidatus Phytoplasma oryzae'.
Rice yellow dwarf disease continues to be a problem for rice farmers in many regions of Asia. Infected rice (Oryza sativa) turns pale yellow and gradually starts to decay; it ultimately shows stunted growth and fails to produce grain. For many years after its discovery in 1919 (Anonymous, 1919), the agent that caused this disease was unknown and was believed to be a virus, until it was identified as a phytoplasma (then called a mycoplasma-like organism) (Nasu et al., 1967). The causative agent, RYD phytoplasma, is transmitted by the leafhoppers Nephotettix cincticeps, Nephotettix virescens and Nephotettix nigropictus, and is present in most rice-growing countries in Asia (Ou, 1985; Nakashima \& Murata, 1993). From its $16 \mathrm{~S}$ rDNA sequences, geographical distribution and the specificity of its host and insect vector, RYD phytoplasma has been regarded as an independent taxon by Namba et al. (1993a) and Nakashima et al. (1993).

\footnotetext{
Abbreviations: BGWL, bermuda grass white leaf; BraWL, brachiaria grass white leaf; OY, onion yellows; Rhp, rape phyllody; ROL, rice orange leaf; $R Y D$, rice yellow dwarf; SCWL, sugar cane white leaf.

The GenBank/EMBL/DDBJ accession numbers for the 16S rDNA sequences reported in this paper are $A B 052870$ (ROL), AB052871 (BGWL-KK), AB052872 (BraWL-KK), AB052873 (RYD-Th) and AB052874 (SCWL-Ud).
}

RYD phytoplasma has been classified in the RYD 16S-group (Jung et al., 2003). Its closest known relatives, based on $16 \mathrm{~S}$ rDNA phylogenetic analyses, are the phytoplasmas associated with sugarcane white leaf (SCWL) and sugarcane grassy shoot (SCGS) found in sugarcane (Saccharum officinarum), annual bluegrass white leaf (ABGWL) found in annual bluegrass (Poa annua), bermuda grass white leaf (BGWL) in bermuda grass (Cynodon dactylon) and brachiaria grass white leaf (BraWL) in brachiaria grass (Brachiaria spp.) (Schneider et al., 1995; Nakashima et al., 1996; Lee et al., 1997; Wongkaew et al., 1997; Tran-Nguyen et al., 2000). Although these phytoplasmas have many traits in common, such as symptoms (leaf chlorosis and proliferation of tillers in most cases) and host plants (gramineous plants), they have not been characterized in detail and little is known of the variability of the group. To determine whether RYD phytoplasma constitutes a discrete, coherent taxon, RYD isolates from two different areas, Japan and Thailand, were analysed and compared with other phytoplasmas studied to date.

RYD phytoplasma samples from rice plants showing typical yellow dwarf symptoms were collected at Tochigi, Japan, and designated RYD Japanese isolates (RYD-J). The 
RYD-J phytoplasma was maintained in rice plants and green rice leafhoppers ( $N$. cincticeps). Reference phytoplasma samples of the BGWL Thai isolate (BGWL-KK) and the BraWL Thai isolate (BraWL-KK), both collected in Khon Kaen, Thailand, and the SCWL Thai isolate (SCWL-Ud), collected in Udonthani, Thailand, have been described previously (Nakashima \& Hayashi, 1995). In 1997, these referenced phytoplasma samples were re-collected. Samples from rice plants showing yellow dwarf symptoms in Thailand and those showing rice orange leaf (ROL) symptoms in the Philippines were collected and designated RYD Thai isolate (RYD-Th) and ROL Philippine isolate (ROL-Ph), respectively. Total nucleic acids were extracted from tissues, as described elsewhere (Namba et al., 1993b), for use as PCR templates. A pair of previously designed primers (SN910610/SN011119; Jung et al., 2003) was used to amplify $16 \mathrm{~S}$ rDNA from each sample tested. The following thermal cycling program was used: 30 cycles of $30 \mathrm{~s}$ at $94^{\circ} \mathrm{C}, 30 \mathrm{~s}$ at $55^{\circ} \mathrm{C}$ and $90 \mathrm{~s}$ at $72^{\circ} \mathrm{C}$, with a final elongation step of $7 \mathrm{~min}$ at $72^{\circ} \mathrm{C}$. Direct PCR using the primer pair SN910610/SN011119 amplified a fragment of the phytoplasma $16 \mathrm{~S} \mathrm{rDNA}$ of approximately $1.8 \mathrm{kbp}$ in all the diseased plants examined (data not shown).

To investigate the phylogenetic relationships between phytoplasmas that infect gramineous plants, $16 \mathrm{~S}$ rDNA of several gramineous plant-infecting phytoplasma isolates, including two RYD isolates, was sequenced. Primers used to sequence the 16S rDNA were reported previously (Namba et al., 1993b; Jung et al., 2003). Nearly complete 16S rDNA sequences were determined for the five novel isolates (RYDTh, ROL-Ph, BGWL-KK, BraWL-KK and SCWL-Ud) and for one of the reported isolates (RYD-J). Almost complete $16 \mathrm{~S}$ rDNA sequences were determined unambiguously (see Fig. 1 for accession numbers). These sequences were compared with each other and with those already reported in the database. $16 \mathrm{~S}$ rDNA sequence analysis revealed that ROL-Ph is most closely related to onion yellows (OY) phytoplasma from Japan (Namba et al., 1993a) and rape phyllody (Rhp) phytoplasma from the Czech Republic (Bertaccini et al., 1998), both of which belong to the aster yellows subgroup of the AY 16S-group (Jung et al., 2002). Judging from the $16 \mathrm{~S}$ rDNA sequence similarity between ROL-Ph and OY (99.9\%), Rhp (99.8\%) and the other aster yellows subgroup members $(98 \cdot 9-99 \cdot 8 \%)$, it is reasonable to classify the ROL phytoplasma in the AY $16 \mathrm{~S}$-group, thus distinguishing it from RYD, which belongs to the RYD 16S-group (Jung et al., 2002). The ROL phytoplasma is transmitted by a leafhopper, Recilia dorsalis (Rivera et al., 1963; Hibino et al., 1987). The 16S rDNA sequences of the two RYD phytoplasma isolates, RYD-J and RYD-Th, were nearly identical $(99 \cdot 2 \%)$, confirming that these two isolates belong to the same species. In addition, the sequence of SCWL-Ud was almost identical $(99 \cdot 8 \%)$ to the reported sequence of SCWL-Th (accession no. X76432; Seemüller et al., 1994). The sequence of BGWL-KK was $99.9 \%$ similar to that of another Thai isolate, BGWL-Th (accession no. AF248961; Davis \& Dally, 2001), but only $97 \cdot 9 \%$ similar to that of an Italian isolate, BGWL-It (accession no. Y16388; Seemüller et al., 1998), indicating heterogeneity among BGWL isolates. Unexpectedly, BraWL-KK was $99.9 \%$ similar to a phytoplasma that infects a different host, BGWL-Th, suggesting that these two phytoplasmas belong to the same species-level taxon. When the 16S rDNA sequences of the two RYD isolates were compared with those of other phytoplasma isolates in the RYD 16S-group, the sequence similarity ranged from $96.3 \%$ (RYD-J vs BGWLIt) to $97 \cdot 9 \%$ (RYD-J vs BGWL-Th). The RYD, BGWL and SCWL phytoplasmas were previously shown to belong to the RYD 16S-group and data in this study suggest that BraWL should also be classified in this group.

The 16S rDNA sequences of the RYD phytoplasmas and related phytoplasmas in the RYD 16S-group (RYD-J, RYDTh, BGWL-Th, BGWL-KK, BraWL-KK and SCWL-Ud) were compared with sequences from phytoplasmas of other groups. The base positions were numbered as described previously (Namba et al., 1993a). Sequence analysis of the phytoplasmas of the RYD 16S-group indicated that there are several signature sequences unique to this group: 5'-AACACTG-3' (positions 604-610) and 5'-GCAA-3' (999-1002) are not found in any other phytoplasmas belonging to other 16S-groups. In the RYD 16S-group, 5'-TATCAGACTA-3' (626-635) is also conserved, with just two exceptions: SCWL and BVK phytoplasmas have T instead of C (629). Additionally, 5'-AAATCTTCGGATTTT-3' (61-75) is conserved, except in the RYD isolates; both RYD-J and RYD-Th have T instead of C at position 65 . Interestingly, this sequence alteration clearly distinguishes the RYD phytoplasmas from other RYD 16S-group isolates. The RYD phytoplasmas also possessed other unique 'signature' nucleotide alterations not found in any other phytoplasmas, including RYD 16S-group isolates. For example, single bases of RYD phytoplasma $16 \mathrm{~S}$ rDNA differed from the corresponding sequences in all other phytoplasmas at positions 149 ( $\mathrm{G}$ to $\mathrm{A}$ ), 181 (C to $\mathrm{T}$ ), 263 (A/C to T), 1148 ( $\mathrm{G}$ to A), 1409 (A to $\mathrm{G}$ ) and 1447 ( $\mathrm{G}$ to A). The presence of these RYD-specific signature sequences in the $16 \mathrm{~S}$ rDNA provides evidence for the genetic divergence of this pathogen from other phytoplasmas.

To clarify the phylogenetic relationships between RYD phytoplasma and the other RYD 16S-group phytoplasma isolates, almost complete $16 \mathrm{~S}$ rDNA sequences $(\sim 1.4 \mathrm{kbp})$ from 48 phytoplasmas and a related mollicute, Acholeplasma laidlawii, as an outgroup, were aligned using the program CLUSTAL W (version 1.6) (Thompson et al., 1994). A distance matrix and phylogenetic tree were constructed with CLUSTAL W using the neighbour-joining method (Saitou \& Nei, 1987). Genetic distances between the sequences were estimated using the $K_{\text {nuc }}$ value (Kimura, 1980). Confidence values (\%) were estimated by the bootstrap sampling method (100 replicates). Sequences of the other organisms used in this study were obtained from DDBJ (http://www. ddbj.nig.ac.jp/). The sources of the $16 \mathrm{~S} \mathrm{rDNA}$ sequences used in this study are listed in Table 1. The RYD 16S-group 
Table 1. Strains of phytoplasmas and Acholeplasma used in this study and associated diseases

\begin{tabular}{|c|c|}
\hline Strain & Associated plant disease \\
\hline AAY & American aster yellows \\
\hline $\mathrm{AlmWB}-\mathrm{A} 4^{\mathrm{T}}$ & Almond witches'-broom \\
\hline AP & Apple proliferation \\
\hline $\operatorname{AshY} 1^{\mathrm{T}}$ & Ash yellows \\
\hline AUSGY & Australian grapevine yellows \\
\hline BWB & Buckthorn witches'-broom \\
\hline BGWL-It & Bermuda grass white leaf \\
\hline BGWL-KK & Bermuda grass white leaf \\
\hline BraWL-KK & Brachiaria grass white leaf \\
\hline BVGY & Buckland valley grapevine yellows \\
\hline BVK & $--^{*}$ \\
\hline $\mathrm{CbY}$ & Chinaberry yellows \\
\hline CirP & Cirsium arvense phyllody \\
\hline $\mathrm{CnWB}$ & Chestnut witches'-broom \\
\hline $\mathrm{CP}$ & Clover proliferation \\
\hline PPWB & Caribbean pigeon pea witches'-broom \\
\hline ESFY & Erigeron witches'-broom \\
\hline EY & Elm yellows \\
\hline FD & Flavescence dorée of grapevine \\
\hline GaLL & Galactia little leaf \\
\hline GLL-Eth & Ethiopian Gliricidia little leaf \\
\hline HibWB & Hibiscus witches'-broom \\
\hline IBS & Italian bindweed stolbur \\
\hline JHP & Japanese Hydrangea phyllody \\
\hline $\mathrm{JWB}-\mathrm{G} 1^{\mathrm{T}}$ & Jujube witches'-broom \\
\hline LDG & Coconut lethal yellowing \\
\hline LDT & Coconut lethal yellowing \\
\hline LfWB & Loofah witches'-broom \\
\hline LY & Coconut lethal yellowing \\
\hline OY & Onion yellows \\
\hline PinP & Pinus sylvestris yellows \\
\hline PpYC & Papaya yellow crinkle \\
\hline ROL & Rice orange leaf \\
\hline RYD-J ${ }^{\mathrm{T}}$ & Rice yellow dwarf \\
\hline SbS & Sorghum bunchy shoot \\
\hline SCWL-Ud & Sugarcane white leaf \\
\hline SpaWB & Spartinum witches'-broom \\
\hline StLL & Stylosanthes little leaf \\
\hline STOL & Capsicum annuum stolbur \\
\hline ViLL & Vigna little leaf \\
\hline WBDL & Lime witches'-broom \\
\hline WTWB & Weeping tea tree witches'-broom \\
\hline WX & Western X-disease \\
\hline Acholeplasma laidlawii & - \\
\hline
\end{tabular}

${ }^{\star}$ BVK phytoplasma originates from a leafhopper, Psammotettix cephalotes, and has no associated disease.

forms a stable phylogenetic cluster in the tree, as judged by branch lengths and bootstrap values (100\%). However, the RYD 16S-group cluster contains several internal nodes with weak bootstrap values, which also reflect an internal branching order that is slightly different from previous results (Seemüller et al., 1998; Jung et al., 2002). This highlights the difficulty in depicting subgroups within the RYD 16S-group using the internal branching order (Fig. 1). The bootstrap value $(100 \%)$ at the actual node indicates statistical support for BGWL and BraWL phytoplasmas sharing a common ancestral node. However, 16S rDNA sequence identity alone may not be enough to classify RYD phytoplasma as an independent species-level taxon.

It has been proposed previously that two phytoplasma isolates should be considered to belong to different specieslevel taxa if their $16 \mathrm{~S}$ rDNA similarity is less than $97 \%$ or if their biological features, such as host plant or vector insect, are distinct (Jung et al., 2002). Recently, the Phytoplasma and Spiroplasma Working Team of the International Research Program on Comparative Mycoplasmology (IRPCM) announced their recommendation that two phytoplasmas that have less than $97 \cdot 5 \% 16 \mathrm{~S}$ rDNA sequence similarity may be designated two separate 'Candidatus Phytoplasma' species, and that those that have more than $97 \cdot 5 \% 16 \mathrm{~S}$ rDNA similarity may be designated separate species only if they can satisfy the following three criteria: (i) they are transmitted by different vectors; (ii) they have different natural plant hosts; and (iii) there is evidence of molecular diversity between the two phytoplasmas (Anonymous, 2002). All of these criteria are clearly met by RYD phytoplasma as follows. Only three species of leafhopper (Nephotettix spp.) transmit RYD phytoplasma, and no other insect vectors have been reported. These insect species are distributed only in Asia (Ou, 1985) and the diseases are naturally restricted to Asia (Nakashima et al., 1993). It is also believed that RYD phytoplasma infects only rice (Oryza sativa) under natural conditions. Evidence for the spread of RYD phytoplasma from rice to other gramineous plants is limited, although it is believed to occur through root grafts and occasionally by leafhopper transmission. The plant-host specificity of RYD phytoplasma in nature may be associated with insect-vector feeding preferences, which are controlled by biophysical and biochemical mechanisms (Viswanathan \& Kalode, 1986) and ultimately by genetic factors. The plant-host specificity may also be due to resistance of a particular plant, since RYD phytoplasma has not been transmitted by a dodder into periwinkle plants. Southern blot analyses showed that one chromosomal and six extrachromosomal DNA fragments of RYD phytoplasma hybridized only with DNA from plants infected by RYD, and not with those infected with other phytoplasmas, including the closely related SCWL phytoplasma (Nakashima et al., 1993). All these lines of evidence and our findings in this study support the recognition of RYD phytoplasma as a unique, novel species-level taxon. The results of base-by-base comparisons of the RYD sequence are consistent with the hypothesis that the RYD subgroup should be regarded as a separate taxon. The geographical distribution of RYD phytoplasma in Asia may have provided ecological isolation, favouring the evolution of a distinct RYD phytoplasma. The presence of 


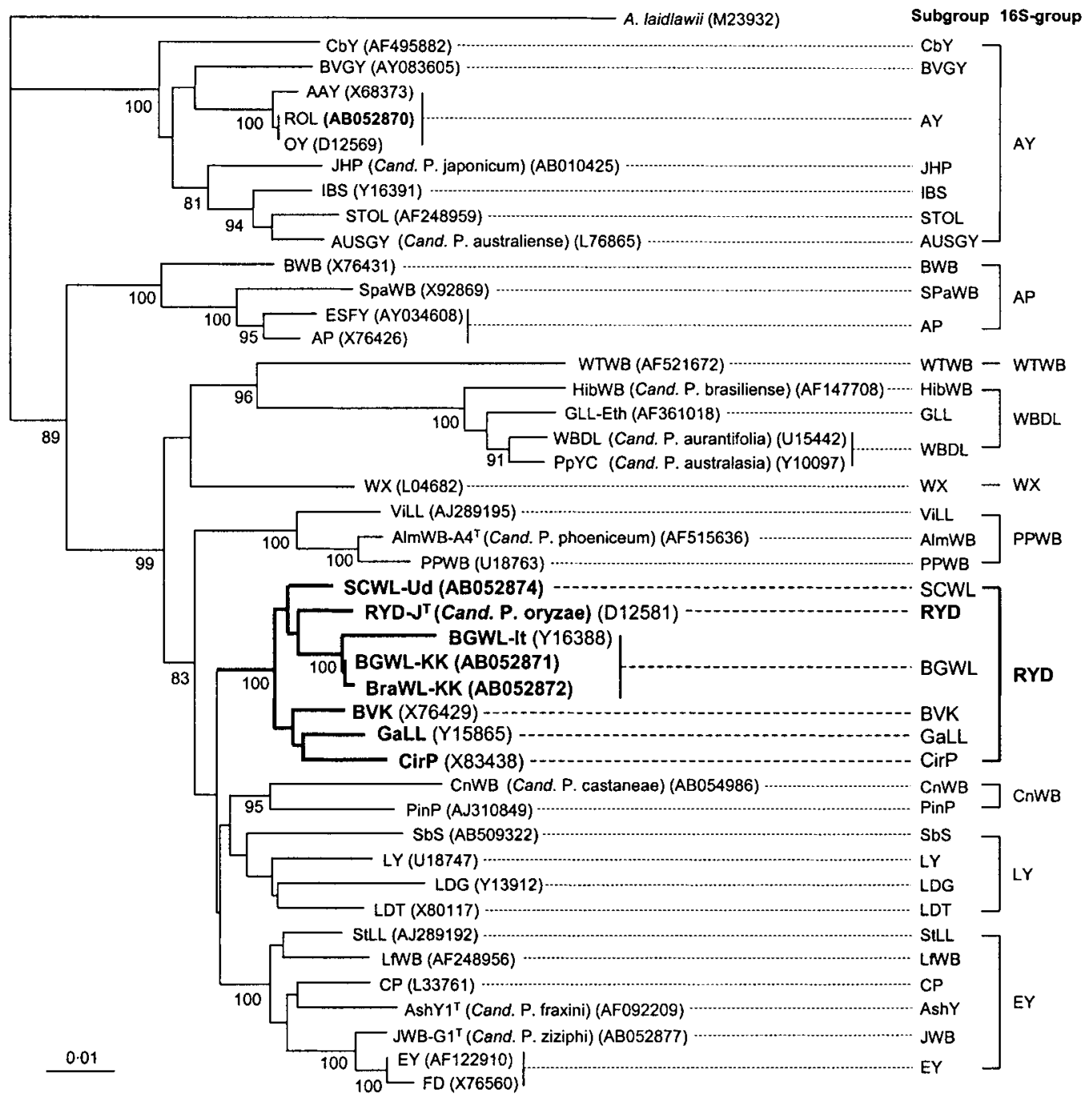

Fig. 1. Phylogenetic distance tree constructed by the neighbour-joining method, comparing the $16 \mathrm{~S}$ rDNA sequences of RYD phytoplasma with those of other representative phytoplasmas from GenBank. Acholeplasma laidlawii was used as the outgroup. Accession numbers are shown in parentheses; those determined in this study are in bold. Numbers on branches are confidence percentages obtained from 100 bootstrap replicates (only values above $80 \%$ are shown). The corresponding phylogenetic group and subgroup names reported previously (Jung et al., 2003) are shown on the right. Bar, phylogenetic distance of $1 \%$. Phytoplasma abbreviations are given in Table 1; Cand., Candidatus.

RYD-specific signature sequences and sequences unique to RYD phytoplasma in the $16 \mathrm{~S}$ rDNA sequence also support this proposition and provide evidence for the genetic divergence of this pathogen from other phytoplasmas. It has been demonstrated that RYD phytoplasma isolates are phylogenetically distinct from all previously described strains belonging to the 'Candidatus Phytoplasma' genus and it is proposed that they should be designated a novel Candidatus species with the following description: 'Candidatus Phytoplasma oryzae' [(Mollicutes) NC; NA; O; NAS (GenBank numbers D12581 and AB052873), oligonucleotide sequences of unique regions of the $16 \mathrm{~S}$ rDNA $5^{\prime}$-AACTGGATAGGAAATTAAAAGGT-3' and 5'ATGAGACTGCCAATA-3', P (rice, phloem); M].

\section{Acknowledgements}

We thank Mr Shigeru Hatano for his excellent technical assistance. This work was supported partly by grants-in-aid from the Ministry of Education, Science and Culture of Japan (nos 09460155 and 13306004) and by the program for Promotion of Basic Research Activities for Innovative Biosciences (PROBRAIN) of the Ministry of Agriculture, Forestry and Fisheries of Japan.

\section{References}

Anonymous (1919). Annual Report 62. Japan: Kouchi Agricultural Research Institute.

Anonymous (2002). Phytoplasma and Spiroplasma Working Team. In International Research Program on Comparative Mycoplasmology 
(IRPCM) of the 14th International Organization for Mycoplasmology (IOM) Report of Consultations, 7-12 July 2002, Vienna, Austria.

Bertaccini, A., Vorácková, Z., Vibio, M., Fránová, J., Navrátil, M., Spak, J. \& Nebesárová, J. (1998). Comparison of phytoplasmas infecting winter oilseed rape in the Czech Republic with Italian Brassica phytoplasmas and their relationship to the aster yellows group. Plant Pathol 47, 317-324.

Davis, R. E. \& Dally, E. L. (2001). Revised subgroup classification of group $16 \mathrm{SrV}$ phytoplasmas and placement of flavescence doréeassociated phytoplasmas in two distinct subgroups. Plant Dis 85, 790-797.

Hibino, H., Jonson, G. B. \& Sta Cruz, F. C. (1987). Association of mycoplasmalike organisms with rice orange leaf in the Philippines. Plant Dis 71, 792-794.

Jung, H.-Y., Sawayanagi, T., Kakizawa, S. \& 7 other authors (2002). 'Candidatus Phytoplasma castaneae', a novel phytoplasma taxon associated with chestnut witches' broom disease. Int J Syst Evol Microbiol 52, 1543-1549.

Jung, H.-Y., Sawayanagi, T., Kakizawa, S. \& 7 other authors (2003). 'Candidatus Phytoplasma ziziphi', a novel phytoplasma taxon associated with jujube witches'-broom disease. Int J Syst Evol Microbiol 53, 1037-1041.

Kimura, M. (1980). A simple method for estimating evolutionary rates of base substitutions through comparative studies of nucleotide sequences. J Mol Evol 16, 111-120.

Lee, I.-M., Pastore, M., Vibio, M., Danielli, A., Attathom, S., Davis, R. E. \& Bertaccini, A. (1997). Detection and characterization of a phytoplasma associated with annual blue grass (Poa annua) white leaf disease in southern Italy. Eur J Plant Pathol 103, 251-254.

Nakashima, K. \& Hayashi, T. (1995). Extrachromosomal DNAs of rice yellow dwarf and sugarcane white leaf phytoplasmas. Ann Phytopathol Soc Jpn 61, 456-462.

Nakashima, K. \& Murata, N. (1993). Destructive plant diseases caused by mycoplasma-like organisms in Asia. Outlook Agric 22, 53-58.

Nakashima, K., Kato, S., Iwanami, S. \& Murata, N. (1993). DNA probes reveal relatedness of rice yellow dwarf mycoplasmalike organisms (MLOs) and distinguish them from other MLOs. Appl Environ Microbiol 59, 1206-1212.

Nakashima, K., Hayashi, T., Chaleeprom, W., Wongkaew, P. \& Sirithorn, P. (1996). Complex phytoplasma flora in Northeast Thailand as revealed by $16 \mathrm{~S}$ rDNA analysis. Ann Phytopathol Soc Jpn 62, 57-60.
Namba, S., Oyaizu, H., Kato, S., Iwanami, S. \& Tsuchizaki, T. (1993a). Phylogenetic diversity of phytopathogenic mycoplasmalike organisms. Int J Syst Bacteriol 43, 461-467.

Namba, S., Kato, S., Iwanami, S., Oyaizu, H., Shiozawa, H. \& Tsuchizaki, T. (1993b). Detection and differentiation of plantpathogenic mycoplasmalike organisms using polymerase chain reaction. Phytopathology 83, 786-791.

Nasu, S., Sugiura, M., Wakimoto, T. \& lida, T. (1967). On the etiologic agent of rice yellow dwarf. Ann Phytopathol Soc Jpn 33, 343-344.

Ou, S. H. (1985). Virus and MLO diseases. In Rice Diseases, 2nd edn, pp. 1-60. Kew, UK: Commonwealth Mycological Institute.

Rivera, C. T., Ou, S. H. \& Pathak, M. D. (1963). Transmission studies of the orange leaf disease of rice. Plant Dis Rep 47, 1045-1048.

Saitou, N. \& Nei, M. (1987). The neighbor-joining method: a new method for reconstructing phylogenetic trees. Mol Biol Evol 4, 406-425.

Schneider, B., Seemüller, E., Smart, C. D. \& Kirkpatrick, B. C. (1995). Phylogenetic classification of plant pathogenic mycoplasmalike organisms or phytoplasmas. In Molecular and Diagnostic Procedures in Mycoplasmology, vol. 1, pp. 369-380. Edited by S. Razin \& J. G. Tully. San Diego, CA: Academic Press.

Seemüller, E., Schneider, B., Mäurer, R. \& 8 other authors (1994). Phylogenetic classification of phytopathogenic mollicutes by sequence analysis of $16 \mathrm{~S}$ ribosomal DNA. Int J Syst Bacteriol 44, 440-446.

Seemüller, E., Marcone, C., Lauer, U., Ragozzino, A. \& Göschl, M. (1998). Current status of molecular classification of the phytoplasmas. J Plant Pathol 80, 3-26.

Thompson, J. D., Higgins, D. G. \& Gibson, T. J. (1994). CLUSTAL W: improving the sensitivity of progressive multiple sequence alignment through sequence weighting, position-specific gap penalties and weight matrix choice. Nucleic Acids Res 22, 4673-4680.

Tran-Nguyen, L., Blanche, K. R., Egan, B. \& Gibb, K. S. (2000). Diversity of phytoplasmas in northern Australian sugarcane and other grasses. Plant Pathol 49, 666-679.

Viswanathan, K. \& Kalode, M. B. (1986). Host specificity of rice green leafhoppers, Nephotettix virescens (Distant) and Nephotettix nigropictus (Stål). Proc Anim Sci Indian Acad Sci 95, 227-236.

Wongkaew, P., Hanboonsong, Y., Sirithorn, P., Choosai, C., Boonkrong, S., Tinnangwattana, T., Kitchareonpanya, R. \& Damak, S. (1997). Differentiation of phytoplasmas associated with sugarcane and gramineous weed white leaf disease and sugarcane grassy shoot disease by RFLP and sequencing. Theor Appl Genet 95, 660-663. 